\title{
Neumoencéfalo por Proyectil de ARMA de fUego
}

\author{
Pneumocephalus by firearm projectile
}

Brito-Núñez Nafxiel Jesús ${ }^{1}$; Brito-Núñez Jesús David ${ }^{2}$

1 Residente de neurocirugía. Hospital Universitario Ruiz y Páez. Ciudad Bolívar. Estado Bolívar. Venezuela.

2 Estudiante de medicina, miembro de la sociedad científica de estudiantes de medicina (SOCIEM)- Universidad de Oriente. Núcleo Bolívar. Venezuela.

Correspondencia a: jdbn_93@hotmail.com

Palabras clave: Neumoencefalo, proyectil, arma de fuego.

Keywords:

Neumoencephalus, projectile, firearm
Procedencia y arbitraje: no comisionado, sometido a arbitraje externo.

Recibido para publicación: 10 de Marzo del 2017

Aceptado para publicación: 21 de junio del 2017

Citar como:

Rev Cient Cienc Med 2017; 20(1): 49-50
Pacir aciente masculino de 35 años de edad, quien posterior a herida por proyectil de arma de fuego, acude al servicio de emergencia por presentar cefalea tensional y sangrado, con urgencia se realiza Tomografía Axial Computarizada (TAC) evidenciando proyectil alojado en fosa craneal anterior es ingresado con diagnóstico de traumatismo craneoencefálico abierto complicado con neumoencéfalo en fosa craneal anterior . sin ser operado, bajo observación por 21 días cumpliendo antibioticoterapia profiláctica con cefalosporinas, egresa asintomático. Imagen Tomada el 15/07/2016. Servicio de Neurocirugía. Complejo Hospitalario Universitario Ruiz y Páez. Ciudad. Bolívar. Venezuela.s Traumatismos Craneoencefálicos (TCE) son las principales causa de mortalidad en pacientes politraumatizados. Aproximadamente dos tercios de todas las muertes por trauma se asocia a lesiones craneoencefálicas y son responsables del $20 \%$ del total de fallecidos en edades productivas ${ }^{1}$. Éstos pueden ser clasificados de acuerdo a la integridad de la duramadre como abierto y cerrado. Las lesiones primarias causadas por el trauma incluyen herida de cuero cabelludo, fractura de cráneo, conmoción, laceración, daño axonal difuso, lesión de par craneano y congestión cerebral. Las lesiones secundarias locales son: hematoma epidural, hematoma subdural, hematoma intraparenquimatoso hidrocefalia, fistula del líquido cefalorraquídeo y neumoencefalo².

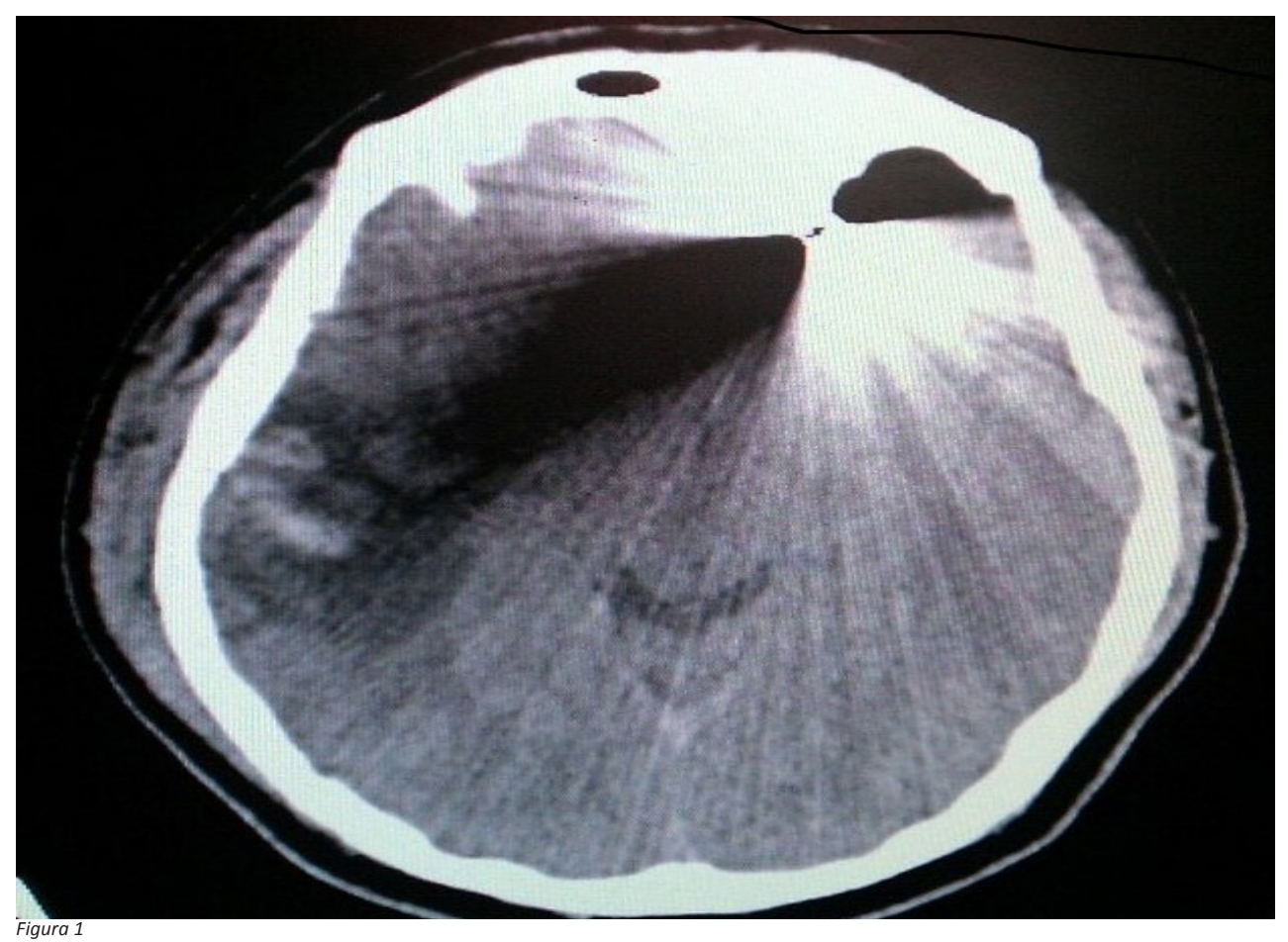


El neumoencefalo representa el 0,3\% de los hallazgos en TAC de cráneo, se localiza frecuentemente en la región frontal, siendo definido como la acumulación de aire dentro de la cavidad craneana, ya sea ventricular, parenquimatoso, subaracnoideo, subdural (más frecuente) y epidural. ${ }^{3}$

El manejo de los pacientes con herida por arma de fuego va a depender de: los síntomas que genere, localización del proyectil, y acce- sibilidad a este, con la consecuente decisión, si es adecuada la intervención quirúrgica o no, se vuelve complicado extraer el proyectil cuando está localizado en áreas de difícil acceso como en la base del cráneo ${ }^{4}$. En el presente caso la decisión de no intervenir quirúrgicamente fue por la clínica del paciente quien solo ingreso con cefalea y posteriormente se encontraba asintomático.

\section{REFERENCIAS}

1. Piña-Tornés A. Manejo del trauma craneoencefálico en la atención primaria en salud. MéD. UIS [Internet]. 2015;28(1):153-158. Disponible en: https://www.google.com/url?sa=t\& $r c t=j \& q=\& e s r c=s \&$ source $=w e b \& c d=1 \& c a d=r j a \& u$ act $=8 \&$ ved $=0$ ahUKEwiWse LFq-DUAhXJZiYKHcQAY4QFggsMAA\&url=https $\% 3 A \% 2 F \% 2 F d i$ alnet.unirioja.es\%2Fdescarga\%2Farticulo\% 2F5168238. pdf\&usg=AFQjCNFrIIPz2M7aeeFAu N3JwiZYNy6WhA

2. Goland J. Traumatismo encefalocraneano. En: Mezzadri JJ, Goland J, Socolovsky M. Introducción a la Neurocirugía [Libro]. Primera edición. Buenos Aires, Argentina: Ediciones Journal; 2011. 44-60.
3. Pérez F, Jacó $\mathrm{N}$. Neumoencéfalo. MED GEN

Y FAM [Internet]. 2016; 5(2):56-58. Disponible en: http://mgyf.org/wp-content/uploads/2017/revistas_ antes/v05n02_006.pdf

4. Rojas-Marroquin A, Cabeza-Morales M, AlvisMiranda H, Alcala-Cerra G, Moscote-Salazar $L$. Heridas por proyectil de arma de fuego en cráneo. Revisión de la literatura. Rev. Chil. Neurocirugía [Internet]. 2015; 41(1):2127. Disponible en: http://www.academia.edu/ download/38485556/Herida_por_proyectil_de_ arma_de_fuego_en_craneo._Revision_de_la_literatura.pdf 